\title{
Teaching Presence in Online Courses: Similar Perceptions but Different Experiences from Multiple Instructor Perspectives
}

\author{
Murat Turk \\ University of Oklahoma, USA \\ Ali Ceyhun Müftüoğlu \\ University of Oklahoma, USA \\ Sinem Toraman \\ Cincinnati Children's Hospital Medical Center, USA
}

\begin{abstract}
Online course instructors' perceptions and perspectives regarding their teaching presence as a key presence in online learning environments significantly influence, if not determine, their online teaching practices, which in turn influence the quality of online students' learning experiences. Although gaining deeper insights into online course instructors' perceptions and experiences of teaching presence is quite important and valuable for online education, there is still limited qualitative inquiry into this critical presence across diverse online teaching contexts. The purpose in this qualitative, multiple case study was to explore and understand online course instructors' perceptions and experiences regarding their own presence in their online courses. We explored the perceptions and experiences of eight course instructors teaching undergraduate and graduate-level online courses at a midwestern U.S. college. Our findings indicated that teaching presence was uniformly considered important and necessary by the instructors although their applications and priorities regarding their teaching presence varied. We discussed our themes that emerged from our interview data and offered several theoretical and practical implications regarding teaching presence in online learning environments.
\end{abstract}

Keywords: Teaching presence, Community of Inquiry, online learning, online teaching

Turk, M., Müftüoğlu, A.C., Toraman, S., (2021). Teaching presence in online courses: Similar perceptions but different experiences from multiple instructor perspectives. Online Learning Journal, 25(4), 156-177. DOI:10.24059/olj.v25i4.2885 
Over the past two decades, there has been an exponential increase in the number of higher education institutions offering online courses and programs (Kucuk \& Richardson, 2019). Most of these institutions have begun considering online education as an integral component of their overall education policy (Berry, 2019; Kozan \& Richardson, 2014; Richardson et al., 2017). The number of college students taking at least one online course as part of their higher education has steadily risen (Seaman et al., 2018). With the growing popularity of online education, the quality and effectiveness of online teaching practices have become a critical topic of interest (Kozan \& Richardson, 2014). In online learning environments, effective and high-quality online teaching practices are made up of course design and organization, facilitation, and direct instruction, including assessment and feedback that are vital to ensure positive student outcomes, such as student satisfaction, perceived learning, and online sense of community (Caskurlu et al., 2020; Shea et al., 2005). Despite their flexibility, accessibility, and convenience affordances, online learning environments still hold unique challenges that involve a sense of isolation as well as psychological, social, and emotional disconnect from peers and instructors (Berry, 2019; Rovai, 2001; Sherblom, 2010). To effectively address these challenges, online learning environments ought to be intentionally designed, developed, and facilitated in line with the principles of effective frameworks tailored for online learning (Kucuk \& Richardson, 2019). The Community of Inquiry (CoI) is a social-constructivist theoretical framework that provides fundamental principles for the design and implementation of online learning and teaching (Kozan \& Richardson, 2014). According to the CoI framework (Garrison et al., 2000), there are three fundamental presences to be fostered and maintained in an online learning environment: (a) teaching presence, (b) social presence, and (c) cognitive presence. All three presences must exist together in an online learning environment because only an effective combination of the three presences fosters deep, meaningful, and high-quality learning experiences (Garrison \& Arbaugh, 2007).

When designed or facilitated poorly, online courses fail not only to create and maintain a strong sense of community, but also fail to provide meaningful, engaging, and satisfying learning experiences for students (Caskurlu et al., 2020; Kucuk \& Richardson, 2019; Rovai, 2002). Therefore, teaching presence is necessary to accomplish positive student outcomes in online learning environments (Gurley, 2018; Kupczynski et al., 2010; Zhang et al., 2016). Despite the key role and importance of teaching presence in online learning environments (Orcutt \& Dringus, 2017), the literature still lacks an in-depth understanding of teaching presence and its three components (i.e., design and organization, facilitation of discourse, direct instruction) from different online course instructors' perspectives, which remain largely unexplored (Gurley, 2018). Such in-depth qualitative exploration of teaching presence from instructors' perspectives is important because deeper understandings of online course instructors' own perceptions and experiences of teaching presence may enrich and expand the CoI framework's teaching presence component across online learning and teaching contexts to improve online teaching practices. Knowledge about online instructors' perceptions of their own presence in online learning environments is invaluable for three reasons. First, online instructors' perceptions of their own presence may influence and even determine their instructional practices and behaviors as well as the learners' online learning experiences in the online courses that they teach (Richardson et al., 2016). Second, the need for further exploration of teaching presence as a key CoI presence in various online learning environments must be addressed, because "there is still much to be learned as contexts change including disciplines, course delivery, and characteristics of the learners, instructors, or both" (Richardson et al., 2016, p. 95). Third, exploration of teaching 
presence directly from online course instructors' perspectives is critical because researchers may gain a deeper and more thorough understanding of the nature and implications of teaching presence in online learning environments (Orcutt \& Dringus, 2017).

\section{Teaching Presence Within the Community of Inquiry}

This qualitative case study was informed by the Community of Inquiry (CoI) framework developed by Garrison et al. (2000) as a product of their empirical inquiries into asynchronous text-based computer conferences in higher education. Garrison and his colleagues (2000) suggested certain elements that they believed were crucial components of online learning environments and named those elements as presences. According to the CoI framework, three online presences must be established and maintained by online participants (i.e., students and instructors) and these are social presence, teaching presence, and cognitive presence (Garrison, 2011). Figure 1 demonstrates the three presences intersecting with each other to create an effective and meaningful online learning environment.

\section{Figure 1}

\section{The Community of Inquiry Framework and Presences}

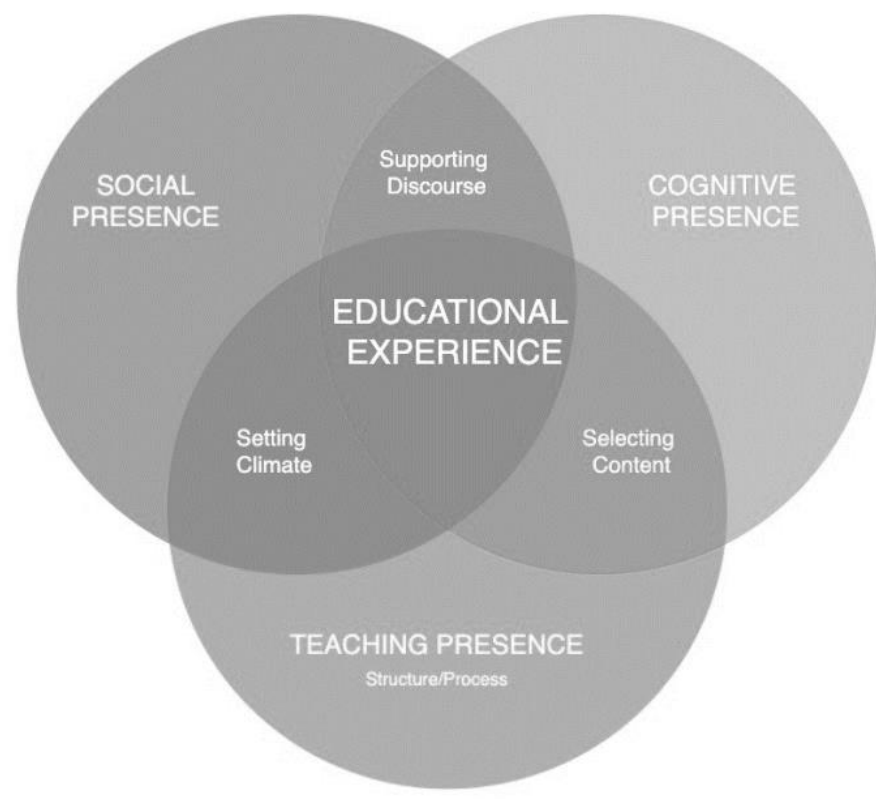

Note: Adapted from Garrison et al. (2000) and used with the authors' permission.

Social presence refers to the extent to which online participants within a learning community can present and establish themselves as well as perceive others as real humans (Garrison et al., 2000; Richardson et al., 2017). Teaching presence refers to basic roles and responsibilities of instructors in online learning environments, including course design, facilitation of student discourse, and direct instruction (Anderson et al., 2001). Cognitive presence refers to the degree to which online learners within a community of inquiry can make meaning out of the course content through critical discourse and communication with others, integrate different pieces of information, and apply their knowledge to new situations to solve problems (Garrison et al., 2000, Garrison, 2011). In the context of this study, teaching presence 
within the CoI framework enabled us to explore different online course instructors' perspectives and experiences in terms of being present in an online learning environment.

\section{Teaching Presence}

Teaching presence is a key presence in online learning that refers to "the design, facilitation, and direction of cognitive and social processes for the purpose of realizing personally meaningful and educationally worthwhile learning outcomes" (Anderson et al., 2001, p. 5). Teaching presence within the CoI framework has a particularly important role because it prescribes what an online course instructor is supposed to do so that high-quality educational and learning experiences can be created for online course participants (Anderson et al., 2001). Relevant literature highlights teaching presence as the binding or key presence within the CoI framework because it serves to create and sustain the necessary climate and foundation for social presence and cognitive presence to emerge and thrive in an online community of inquiry (Anderson et al., 2001; Arbaugh, 2014; Caskurlu et al., 2020; Garrison et al., 2010; Garrison \& Akyol, 2013; Garrison \& Arbaugh, 2007; Kozan \& Richardson, 2014). Hence, teaching presence is the prerequisite presence for the other two presences of the $\mathrm{CoI}$ framework (Ke, 2010).

In line with the theoretical tenets of the CoI, a large body of empirical research indicates that teaching presence is associated with a wide variety of desirable and valuable student outcomes in online learning environments such as online student satisfaction, perceived learning, sense of belonging and community, cognitive presence, and social presence (Akyol \& Garrison, 2008; Arbaugh, 2008; Caskurlu et al., 2020; Garrison \& Akyol, 2013; Garrison \& Arbaugh, 2007; Shea et al., 2005, 2006; Shea \& Bidjerano, 2009). In this study, the strong empirical foundation of teaching presence in relation to these student outcomes informed our exploration of teaching presence from instructors' perspectives because online course instructors are the agents expected to establish and maintain this key presence. Despite the key role and importance of teaching presence in online learning environments (Orcutt \& Dringus, 2017), the literature still lacks an in-depth understanding of teaching presence and its components from different online course instructors' perspectives, which remain largely unexplored (Gurley, 2018). This study fills this gap by providing an in-depth qualitative exploration of teaching presence from instructors' perceptions and experiences and its dimensions across online course contexts.

In the context of this study, we defined and explored teaching presence based on the CoI literature. Accordingly, teaching presence was defined as the design and organization of an online course, facilitation of online student discourse and understanding, and direct instruction including assessment and feedback provided by course instructors for online students. While we acknowledge that teaching presence within the CoI framework is not limited to course instructors only but can rather be distributed across teachers, students, and course materials, for the specific purpose and questions of our study, we focused on teaching presence behaviors, roles, and responsibilities (i.e., design and organization, facilitation, direct instruction) fulfilled by online course instructors (Richardson et al., 2015). We must also acknowledge that although assessment or feedback is not a distinct subdimension of teaching presence as defined in the CoI framework, it can be subsumed by the direct instruction component of teaching presence because "direct instruction also takes the form of statements that confirm understanding through assessment and explanatory feedback." We also used teaching presence and instructor presence interchangeably in the current study when discussing course instructors being present in an online course, although instructor presence was examined as a distinct phenomenon with a primary emphasis on the manifestation of instructor actions and behaviors during online learning as suggested by Richardson et al. (2016). The reason for our interchangeable use of the two concepts here is that 
"instructor presence actions and behaviors were deeply rooted in activities traditionally associated with teaching presence" (Richardson et al., 2016, p. 88).

Informed by the CoI theoretical framework (Garrison et al., 2000), the purpose of this qualitative case study was to explore online course instructors' perceptions and experiences in relation to teaching presence and its three dimensions (i.e., design and organization, facilitation, direct instruction). The following research questions were addressed in this study:

1) What were the instructors' overall perceptions and experiences of being present in online courses?

2) What were the instructor's perceptions and experiences of teaching presence dimensions across online teaching contexts?

\section{Method}

To explore online course instructors' perceptions and experiences in relation to teaching presence and its three dimensions, we employed a qualitative multiple case study design.

Following Yin's (2018) guidance, our rationale for employing multiple case study design was to gain an in-depth and authentic understanding of specific life events or situations within their original contexts or real-life settings to interpret them meaningfully and contextually.

\section{Researcher Positionality}

Given the nature of qualitative research, we need to acknowledge researchers' positionality throughout the research process in this study. Researcher positionality refers to researchers' experiences and contextual embeddedness in the phenomenon studied (Creswell \& Poth, 2018; Harding, 1992; Ponterotto, 2005). The first author identifies himself as an online course faculty and researcher and considered that his positionality enabled him to establish good rapport with the instructors - the participants of this study - during the data collection. He also noted his knowledge about the relevant literature that enabled him to probe further into the issues during the interview and helped him make better sense of the data. The second author, as another growing scholar and researcher, also noted that his knowledge about instructional design and technology, including online learning, enabled him to make better sense of the data together with the first author. The third author has expertise in research methodology, and she provided methodological guidance and consultation throughout the research process as well as bringing her insights through her experience of teaching online.

\section{Description of Multiple Cases}

As highlighted by Creswell and Poth (2018), employing multiple case study design allowed us to reflect as many different perceptions and experiences of online instructors from diverse content domains, experiences, and teaching backgrounds as possible. Multiple case study design also allows researchers to replicate major findings across multiple cases and to compare cases across major findings in terms of similarities and differences (Yin, 2018).

In the context of this study, multiple cases consisted of 16 fully online courses that were taught at a midwestern U.S. college and used as the bounded systems. These sixteen online courses were taught by eight different instructors as part of programs in Adult and Higher Education, FirstYear Composition, Women's and Gender Studies, Library and Information Studies, Health and Exercise Science, Religious Studies, History of Science, Technology and Medicine, and Arts and Sciences General Education. Each of the eight online course instructors who taught online within the bounded systems was treated and used as a case in this study. All the cases were limited to one academic semester as the specific timeframe (i.e., Fall 2019). 
In this multiple case study, we employed two sampling strategies. Initially, we identified potential participants via snowball sampling. Snowball sampling is a sampling strategy that helps researchers identify potential participants through key individuals or organizations having access to potential information-rich participants (Creswell, 2014). The first author emailed online program coordinators from different colleges and departments at the research site and requested them to help us reach out to those information-rich informants (i.e., online course instructors) for our study. In addition to the snowball sampling, we employed criterion sampling. Criterion sampling strategy allows researchers to set a certain set of rules in the context of their study so that they include only those individuals who meet their established criteria (Creswell \& Poth, 2018). Accordingly, when we had a pool of online course instructors, we followed a set of criteria to determine the study participants. Our inclusion criteria for online course instructors were (a) having at least two years' experience in online education and (b) having actively taught at least one fully online course in a higher education setting. We decided to look for at least two years' experience in online teaching because of our interpretation of Richardson et al.'s (2016) categorization of instructors' online teaching experience reported as medium and high, where high experience indicated five or more years of experience in online teaching. We also looked for the second criterion so that the participants could bring relevant and bare minimum of online course experience to our study.

\section{Recruitment Process}

After receiving the Institutional Review Board (IRB) approval, the first author reached out to the online program coordinators from different colleges and departments at the site. Those online course instructors identified through program coordinators as potential information-rich informants were accordingly_via IRB-approved recruitment emails_invited by the first author to participate in this study. Participation was voluntary. Those instructors who agreed to participate in this study filled out an online course instructor demographic information form prepared by the authors. Using the instructors' background information and the inclusion criteria, we recruited those online course instructors meeting our criteria and scheduled interviews with them. This sampling procedure yielded eight online course instructors to participate in interviews.

\section{Participants Characteristics and Study Context}

Of the eight online course instructors, six of them were female and two of them were male. The average age of the participants was $43(S D=8.15)$. Seven participants self-identified as White or Caucasian as their ethnicity; one participant identified as Asian. Majority of the instructors held a doctorate in philosophy (Ph.D.) degree $(n=6)$ in various fields, including Teaching and Learning, Literature, English, Library Studies, and History of Science. The remaining two participants held a master's degrees, one in English and the other in Health and Sports Sciences. All instructors had teaching backgrounds in higher education. Four held fulltime faculty status and three held part-time status. One participant reported that they were not teaching as a faculty member but working full time designing online courses at the time of the data collection.

In terms of receiving formal training in online teaching and course design, considering the three categories of formal training (i.e., online teaching, online course design, and learning management systems), instructors' background varied. Four of the instructors received at least one or two of the training categories (i.e., online course design and learning management systems). One participant received no formal training in any of the three categories, whereas three participants received formal training in all three categories. Regardless of their formal 
training in online learning and online course design, the majority of the participants were somehow involved in course design activities. Only one participant reported that she had not designed any online courses before this study. All the instructors also reported that they usually taught online courses that they had designed. Table 1 presents the characteristics of the participants.

Table 1

Online Course Instructors' Characteristics $(N=8)$

\begin{tabular}{|c|c|c|c|c|c|c|c|c|}
\hline Pseudonym & $\begin{array}{l}\text { Faculty } \\
\text { status }\end{array}$ & $\begin{array}{l}\text { Teaching } \\
\text { background }\end{array}$ & $\begin{array}{l}\text { Years } \\
\text { teaching } \\
\text { online }\end{array}$ & $\begin{array}{l}\text { Number } \\
\text { of } \\
\text { courses } \\
\text { taught } \\
\text { online }\end{array}$ & $\begin{array}{l}\text { Formal } \\
\text { training } \\
\text { in online } \\
\text { teaching }\end{array}$ & $\begin{array}{l}\text { Formal } \\
\text { training } \\
\text { in online } \\
\text { course } \\
\text { design }\end{array}$ & $\begin{array}{l}\text { Formal } \\
\text { training } \\
\text { with } \\
* \text { LMS }\end{array}$ & $\begin{array}{l}\text { Number } \\
\text { of } \\
\text { courses } \\
\text { designed }\end{array}$ \\
\hline Mary & Full-time & Higher Ed & 5 & about 20 & No & No & Yes & 3 \\
\hline Sharon & Full-time & $\begin{array}{l}\text { Higher Ed } \\
\text { and } \\
\text { Corporate }\end{array}$ & 2 & 1 & No & Yes & Yes & None \\
\hline Jessica & Part-time & Higher Ed & 3 & 6 & Yes & Yes & Yes & 2 \\
\hline Luisa & Full-time & Higher Ed & 17 & 6 & No & No & No & 6 \\
\hline Ginger & Part-time & Higher Ed & 15 & 5 & Yes & Yes & Yes & 5 \\
\hline Michael & Full-time & Higher Ed & 5 & $10-15$ & Yes & Yes & No & approx. 5 \\
\hline Thomas & $\begin{array}{l}\text { Non-TT** } \\
\text { staff }\end{array}$ & Higher Ed & 5 & 8 & Yes & Yes & Yes & 12 \\
\hline Jennifer & Full-time & Higher Ed & 9 & about 15 & Yes & No & Yes & 2 \\
\hline
\end{tabular}

Notes: *Learning management system

** Tenure Track

\section{Data Collection}

The data collection involved semi-structured interviews with the eight online course instructors. Before the data collection, each participant read and signed a consent form. Participants were not compensated for their participation.

\section{Semi-Structured Interviews}

Before the interviews, the first and second authors prepared a demographic information form and sent it to those course instructors who agreed to participate in the study. The purpose of the demographic information form was to gather demographic (e.g., age, gender, ethnicity) and background information to capture course instructors' educational and professional experiences in online teaching (e.g., number of years in online education, number of online courses taught). Considering participants' convenience and availability, the first author scheduled the interviews 
and received the confirmations of participation via emails. The interview place was also determined based on the participants' preferences.

The first author conducted seven semi-structured interviews face-to-face and one Skype audio call during the Fall 2019 academic term. All interviews were audio-recorded as stated in the consent form. The average length of the interviews was approximately 30-40 minutes. After obtaining signed informed consents, each participant was asked to respond to a set of semistructured interview questions drawn from an interview protocol (see Appendix A) prepared by the first author as a content expert in CoI's teaching presence and its indicators. A total of 28 questions including both major and probe questions were used during the interviews. Due to the nature of qualitative interviews, the questions were also modified based on participants' responses. When necessary, the first author also used different probing questions based on the natural flow of each interview.

\section{Data Analysis}

The first and second authors transcribed the interview audio files verbatim using an online service and then they checked the transcriptions for accuracy. Following an inductive approach to coding, the two authors read the transcripts to become familiar with the data and employed open coding technique to create initial codes. Inductive coding is applied to allow certain codes, categories, and themes to emerge from the data (Ezzy, 2002; Richardson et al., 2016). Then, the two authors discussed their codes and the description of the initial codes from their analysis of the same transcripts. A set of open codes was freely created to represent online course instructors' perceptions and experiences of teaching presence. As suggested (Ezzy, 2002; Richardson et al., 2016; Yin, 2018), cross-case analysis was employed to identify and discuss similarities and differences among the participants' perceptions and experiences of teaching presence. Cross-case analysis is an approach whereby researchers explore each case on its own and then make comparisons across the cases in terms of the relevant themes (Richardson et al., 2016).

The first two authors developed a codebook and iteratively revised it as new codes and categories emerged from the data. Throughout data analysis, the first two authors independently coded interview transcripts and met weekly to compare their codes for each case. All the discrepancies were fully examined and negotiated until the authors reached a $100 \%$ consensus on the final codes to be employed for the data analysis (Creswell, 2014). After the coding process, the first two authors explored the data for patterns to develop themes with respect to the research questions. Because the research questions called for the in-depth exploration of participants' perceptions and experiences, we used interviews as data collection tools and triangulated the data through multiple coders following the guidelines suggested by Creswell and Poth (2018).

\section{Findings}

In this section, we present our themes that emerged from our data analysis within a crosscase analysis of similarities and differences across cases. Overall, seven themes emerged from the two research questions: (a) being present in multiple forms and ways, (b) clear goals, expectations, and instructions, (c) role of feedback in online course design, (d) autonomysupportive online course design, (e) multiple instructor roles in facilitating online student discourse, (f) sense of community and student outcomes, and (g) assessment and grading approach. While being present in multiple forms and ways theme was associated with our first research question and revealed the instructors' overall perceptions and experiences of being present, the other six themes reflected instructors' perceptions and experiences of teaching 
presence dimensions across online teaching contexts. Accordingly, we organized these themes within two broad sub-headings: Being present in multiple forms and ways and instructors' perceptions and experiences of teaching presence dimensions across contexts.

\section{Being Present in Multiple Forms and Ways}

In relation to our first research question - What are the instructors' overall perceptions and experiences of being present in online courses? - we first asked each participant a general question regarding their overall understanding of teaching or instructor presence in an online learning environment. All instructors perceived being present to be quite important in one way or another. One of the instructors, Mary, for example, emphasized the human element, while discussing the importance of being present in an online course. As Mary stated:

\section{Even though we're not meeting face-to-face, the students don't feel like it's a canned course and it doesn't feel like they're just interacting with a robot. You know that there's a human being who is still their instructor and cares about their learning.}

In general, being present was also perceived by some course instructors as emerging at different levels in the online learning environment. For example, Jennifer seemed to perceive being present not only at the interaction or engagement level during the course but also at the design level even before the course started. Jennifer said, "So I see it [being present] as coming out in the modules, making sure that your voice is in there, it's not just a bunch of links to outside courses..." Similarly, Sharon discussed how she intentionally designed certain components of the course to reflect herself as a real human in the online learning context. Sharon noted, "I was very intentional when I thought about how I wanted this class to be created and thinking about what are some of the different steps that I could take to still have that human connection." Different from other instructors, Luisa described her perception and experience of as being a supporter or a coach who motivates, guides, and helps online students. Luisa said, "I see myself as helping the students have asked, I want to make them excited about what they're doing. So I'm kind of a coach and a cheerleader. That's how I think about it [being present]."

\section{Instructors' Perceptions and Experiences of Teaching Presence Dimensions Across Contexts}

In relation to our second research question - What are the instructor's perceptions and experiences of teaching presence dimensions across online teaching contexts? - six themes emerged from our data analysis addressing online course instructors' perceptions and experiences of instructional design and organization, facilitation of student discourse and learning, and direct instruction including assessments and feedback.

Most of the instructors perceived the instructional design and organization of their online courses as being quite important. For example, Jennifer expressed the important effect of course design on course quality as perceived by online students and said, "I could see if the course was designed kind of terribly by an instructor who's not very engaged or who doesn't care, I could see it probably being a nightmare for students to take." Luisa seemed to view course design and organization as the most important teaching presence component or level. Luisa said, "I guess it's, the most important thing I do is to make sure that all the pieces fit together," highlighting the significance of the designer and organizer role of online course instructors. Similarly, Sharon stated that she felt like she was responsible ultimately for the design of her course and she 
perceived the significant impact of online course design on her online students' learning experiences in her courses. She said,

I try to look at it with the view of what's going to be easiest for the students to follow, what's going to make the most sense, what is going to be chunked into groups of information that will help them to be able to flow through completing their assignments and understand the information the best.

\section{Clear Goals, Expectations, and Instructions}

The first theme that emerged in relation to our second research question was the guiding role of course goals, expectations, and instructions. Just like in a face-to-face course, course goals, expectations, and instructions were perceived and experienced by online course instructors as important elements guiding the design and organization of an online course. Although not all instructors intentionally thought about the formal instructional design process, they still had certain goals and expectations in mind for their students to achieve and fulfill in their online courses. For example, Mary stated that when she was planning a new online course, she was not thinking about a formal instructional design process, but still wanted to teach certain content and wished to assess student learning in certain ways throughout her online course, suggesting she still had certain specific goals to achieve, which also guided her own design and organization. In addition, clear goals and expectations conveyed to students as part of a skillfully designed and organized online course were perceived as positively influencing online students' academic work. For instance, Sharon discussed such positive effects of clear goals and expectations and said:

I think the more organized that I am in the way that I present it, and the more detail I can provide to them in terms of their instructions on the expectations, the more successful they are in completing the work.

Another instructor mentioned using students' exemplary work as task instructions showing students what they are expected to do and how they can do it. Luisa discussed her use of exemplary student work in a blog environment and said, "And I can actually show examples of student work, which is a really powerful learning tool. I think not just hearing from the teacher, but actually seeing what other students are doing." Most of the other instructors used similar traditional ways of providing instructions and directions, such as using rubrics and giving instructions in the tasks and assignments themselves.

\section{Role of Feedback in Online Course Design}

The second theme was the role offeedback in online course design. One of the online course instructors, Luisa, insistently emphasized the role of feedback in the design of her fully asynchronous online courses by indicating that her entire online course design was based on a system of feedback loops:

When I'm designing the course, I make sure that it's clear how there's going to be feedback for the work that everybody is doing. So either peer-to-peer feedback or feedback from me to the students or how I'm going to get feedback from the students 
about my job and how well I'm doing. So I do a lot of course design, I work on that pretty hard. And what I'm always looking for are the feedback loops.

Luisa's emphasis seemed to suggest that it was feedback loops that primarily accounted for her entire online course design and organization, which was quite different from the other cases in this study.

\section{Autonomy-Supportive Online Course Design}

The third theme was autonomy-supportive online course design, allowing for choice and learner control. Thomas discussed how he intentionally designed his online courses in a way that would allow his online students to choose from among topics and issues to study and discuss with each other. As he stated:

I try to design with a lot of flexibility for the students in mind. And so, the first thing that I think about is student autonomy... And so student choice and helping students understand that choice is what I'm designing for.

\section{Multiple Instructor Roles in Facilitating Online Student Discourse}

The fourth theme was multiple instructor roles in facilitating online student discourse. We found that instructors shifted from one role to another in their online courses to achieve specific goals across online teaching contexts. One instructor mentioned not engaging much with their students' postings and interactions but rather intervening only when he thought the discourse was not going anywhere, while another instructor discussed the practice of redirecting the students' discourse to the major points that she wanted them to think about during online discussions. Overall, the instructors who utilized online discussions in their courses suggested using discussion prompts or questions to promote student discourse in one way or another and asking the students to interact with their peers in a constructive and respectful way. One of the instructor roles we identified in our case study was associated with being a model for online students. One instructor, Ginger, discussed the importance of demonstrating at the beginning of the course what effective online discussions and discourse would look like so that the students could follow suit accordingly. Ginger explained:

For the first two or three weeks, I think my role is the [emphasized] instructor. So I heavily involve with the topics, every topic, every student's post, to demonstrate what an effective online discussion board should be...So from week four or so, students pick the week or the chapters they would like to discuss. So they will be the [emphasized] instructor for their group, small group.

The primary instructor role in such student-led online discussions shifts from the instructor conveying the major messages to the instructor monitoring student discourse with minimal intervention being used only when necessary. Jennifer discussed the necessity of minimal instructor involvement in students' conversations to encourage more active student ownership of those conversations. Jennifer said:

I actually just kind of sit back and let them discuss. I used to try to go in and engage in the conversations and I was concerned that it was like making some of them more 
nervous about posting, because I would be talking with them... For the most part, what I do is I just let them respond to each other.

We identified this instructor role as being a guiding and facilitating moderator. However, the level of instructor involvement in online student discourse within this role still varied across the instructors. For example, Mary explained her role in online discussions as trying to monitor and respond to as many student postings as possible and said, "I read every response. And I try to comment on everybody, but I can't always, it's just a lot, but especially when somebody expresses a viewpoint that is different from most of the students."

\section{Sense of Community and Student Outcomes}

The fifth theme was sense of community and student outcomes. Almost all the instructors seemed to agree that having a sense of community in online learning environments was important. For example, Jennifer explained:

I actually really want them [students] to get to feel like a community... so, I really try to start it with the first assignment where they do introductions, they have to respond to three other people's introductions. And so I start it there, and it's very intentional... Because I want them to feel connected to me and to each other.

We found that sense of community was perceived important not only for its affective outcomes, such as positive feelings of relatedness and connectedness, but also for its different learning outcomes. For instance, Jennifer seemed to suggest that having a sense of community encouraged her online students to read and review their peers' papers with more care and higher quality, helping them to make greater effort to learn how to give quality feedback to others. As Jennifer explained:

I think that they [students] feel more responsibility to each other...And so they're assigned a peer that they work with. And I usually try to assign, pair them up with somebody who's in a similar field to them. And so then I feel like they feel all the more obligated to try to give them good feedback, because "this is my colleague," you know.

On the other hand, three instructors discussed the difficulty of fostering a sense of community and seemed to not feel so confident or happy about their ability to do it effectively in their online courses. Mary discussed her own online learning experience and suggested that she believed it is very difficult for online students, especially for those not knowing each other personally, to develop a sense of community, although they might feel like friends. Similarly, Michael reported that he could do more about it and he was still looking for ways to do it better. Likewise, Sharon discussed how difficult she believed it was to foster a sense of community in online courses and expressed her desire to learn more about it. As Sharon explained:

I think there's definitely value to it [sense of community]. I do think it's important, but I don't think that I've mastered how to do it. I feel like it's very difficult to do... I would love to know how to do a sense of community better in an online class. 
Jessica mentioned a different challenge she perceived regarding fostering sense of community among online students. She indicated that online course size would have a significant impact on her ability to do things about sense of community in her online courses. As Jessica explained, "So, creating community is done better, for sure, in smaller classes, whether it be face-to-face or online. So, limiting, if creating a community is important for programs or for courses, limiting the number of students is huge."

\section{Assessment and Grading Approach}

The sixth theme was assessment and grading approach. We found that the instructors adopted a wide range of approaches while assessing and grading their online students' work and learning performance. Their approaches ranged from giving small quizzes to rubric-based assessments, self-regulated assessments, and even an un-grading pedagogy. For example, Ginger pointed out that she used short quizzes to check her students' understanding of basic concepts for formative assessment purposes. Mary indicated that she graded her students' discussion postings based on a set of criteria such as the word limit and responses to peer comments. She also gave two to three multiple-choice quizzes in one of the two online courses she taught while she assigned a certain number of practice exercises as assignments in her other online course. Jessica, however, noted that she did not use objective assessments (e.g., multiple-choice tests) but rather assessed her students' work through the students' writing due to the nature of the course she taught. She also followed a rubric, albeit not so strictly. As Jessica explained, “I don't do a whole lot of varied stuff. I don't do like quizzes or multiple-choice stuff. Like I don't do anything like that. It's all through writing."

Unlike all the other instructors who participated in this study, two instructors, Luisa and Thomas, seemed to follow a different approach to assessment and grading. Luisa mentioned using no traditional assessments, but rather having her online students self-monitor and selfrecord their own work progress in the LMS so that their final grades would emerge because of all these self-reports. She reported adopting quite a formative approach in her assessment and grading. As Luisa explained:

And I don't grade, by the way, I'm an un-grader, so all the feedback that they [students] are getting is in terms of, "here's the progress you've made, here's where you could make some more progress." And it's all very progress and processoriented without grade, without numbers.

Since Luisa taught college writing rather than a specific subject domain, she seemed to be more able to adopt such a feedback-based, ungraded approach to assessment because there seemed to be no specific content knowledge to be acquired and reproduced by her online students. Thomas, who followed a very similar approach to assessment and grading, also expressed his dislike of traditional assessment and grading approaches. Like Luisa, he emphasized the role of feedback loops in his pedagogical approach to assessment and underscored his use of formative assessment as well. As he explained, “The model that I like best is un-grading. And I don't mean like not grading, I mean, just recursive, iterative feedback loops, and so thinking of almost everything as formative assessment rather than summative."

\section{Discussion}

Our multiple case study provides new insights into diverse manifestations of CoI's teaching presence across online contexts. We believe that different experiences of teaching 
presence by online course instructors can expand our understanding of teaching presence and its dimensions in online learning environments.

\section{Overall Perceptions and Experiences of Being Present in Online Courses}

The results of this study indicate that being there for their students in an online learning environment was perceived by the interviewed course instructors to be important and essential, which is in line with prior research (e.g., Martin et al., 2019). In addition, course instructors' overall understanding of being present in an online learning environment may not be limited to instructors' specific actions and behaviors during the course, as indicated by Richardson and her colleagues $(2015,2016)$, because we found in this study that being present in an online course could be perceived and experienced by instructors as a component of course design as well (e.g., design of modules). Some instructors seemed to imply that they could still project themselves as real people even before the course starts through their instructional designs. Incorporating the pre-course design dimension into the perception of a course instructor being present in an online course supports Richardson et al.'s (2015) conceptualization of instructor presence as the intersection of teaching and social presences but with one important difference. Unlike their primary emphasis on the during-course characteristic of instructor presence and specific instructor actions and behaviors during an online course, being present in an online course might also be perceived and experienced by some instructors as their course design being experienced by their students. Although instructor presence as a comprehensive construct involves instructional design (Richardson et al., 2016), this design-included perception of being present seems to be more likely to emerge or to be more salient among those instructors who teach online courses that they themselves design and develop, as our participant instructors did.

We also found that being present as an online course instructor might also be perceived and experienced as being a motivating cheerleader who consistently helps and supports the students in their online learning experiences, which is supported by prior research (e.g., Martin et al., 2019). This perception is also in good alignment with Richardson et al.'s (2015) advocating role of teaching presence enhanced by rich social presence indicators such as promoting excitement and expressing acknowledgement of students' achievement. Reflecting on such different perceptions and experiences of being present in online learning environments may encourage online course instructors, especially novice ones, to start constructing their own presences or profiles in their online courses (Richardson et al., 2015).

\section{Perceptions and Experiences of Teaching Presence Dimensions Across Contexts}

Our findings supported the perceived importance of instructional design and organization in establishing and maintaining teaching presence (Anderson et al., 2001; Caskurlu et al., 2020). Course design and organization have an important role in establishing teaching presence in online learning environments because it is during this design and organization stage where teaching presence can be intentionally planned and constructed by instructors to promote a sense of being there (Martin et al., 2019; Orcutt \& Dringus, 2017). Our findings seem to indicate that whether a formal instructional design process is followed or not before an online course starts, online course instructors seem to always have certain goals and expectations about their students that might vary in specificity or depth depending on instructor priorities or teaching contexts. This implies that the design and organization dimensions (e.g., course goals, instructor expectations) of teaching presence may not always be conceived by course instructors as the precourse component of a formal instructional design process only, but it can also be perceived and experienced as an element that permeates teaching presence at all levels and stages of online 
teaching experiences and instructional practices. Moreover, the positive relationship evident from students' perspectives between design and organization components of teaching presence (e.g., clear goals, expectations, instructions) and positive outcomes in online learning environments such as perceived learning or satisfaction (Caskurlu et al., 2020) was also echoed by our case study from instructors' perspectives regarding perceived positive influence of clear goals and expectations on online students' academic work.

In terms of different experiences of the design and organization dimension of teaching presence, we found that making course expectations and instructions more concrete and comprehensible for online students through the provision of exemplary student work was one particular manifestation of the design and organization dimension of teaching presence, pointing to how the same CoI presence element or dimension commonly perceived to be important could still be practiced and experienced in different ways by different instructors (Orcutt \& Dringus, 2017). Using exemplary peer work and keeping it accessible to students in online courses could be an effective way to ensure online students' thorough understanding of the specific requirements of learning tasks and assignments.

Although feedback is given as an element of the direct instruction component of teaching presence in the CoI framework (Anderson et al., 2001), it also emerged as a key element of online course design and organization in our case study. We believe that this is another good example of how the same teaching presence element could commonly be perceived to be important but still experienced differently by different instructors with their own pedagogical priorities and beliefs. Providing timely and positive feedback is an essential component of online learning expected and appreciated greatly by online students (Watson et al., 2017). In addition, providing timely and positive feedback is positively associated with important online outcomes including perceived teaching presence ( $\mathrm{Li}$ et al., 2020). Our findings indicate that feedback might not be limited to facilitation and/or direct instruction dimension(s) of teaching presence but might also be very well integrated within the entire design and organization of online courses, which we argue should push our thinking about the place of feedback within the CoI framework one step further. Online course instructors as well as instructional designers may also need to consider such a systemic integration of feedback loops into the design and organization of online courses so that one of the most fundamental and valued components of high-quality education can be accomplished. Especially faculty members who are new to online teaching and not used to giving feedback in online learning environments could benefit from this design-based feedback perspective.

Autonomy-supportive course design is another important theme to discuss, although only one of the instructors explicitly mentioned student autonomy. We found it valuable to report autonomy support as an independent theme for the design and organization dimension, because we believe that choice, flexibility, and student control as indicators of student autonomy (Ryan \& Deci, 2017) — in addition to clear goals, instructions, and due dates - might need to be explicitly incorporated into the design and organization dimension of teaching presence within the CoI framework. This autonomy-support perspective might add an additional dimension to the traditional conception of the design and organization component of teaching presence within the original CoI framework and online education model. Designing and organizing online courses for student autonomy should be quite important and valuable just like the design and organization of face-to-face learning environments, because autonomy is one of the basic psychological needs together with competence and relatedness (Ryan \& Deci, 2000). These three basic psychological needs should be optimally satisfied in any learning environments, online or 
offline, so that students can feel motivated and get better engaged with their own learning process (Ryan \& Deci, 2000). Teaching presence with its autonomy-supportive course design and organization could help instructors to achieve this in online learning environments. We believe autonomy-supportive course design and organization is another good example of potential variations in actual experiences of teaching presence across instructors and contexts. We also found that instructor roles might vary in online courses from being a model to being a guiding moderator and a supportive facilitator. Our finding is consistent with the previous research indicating that online course instructors adopt different roles in their interactions with their online students (Martin et al., 2019; Shea et al, 2006). During online discussions, course instructors may exhibit or model appropriate and expected ways of participation by actively demonstrating them, especially in the early days or weeks of the online course (Martin et al., 2019). After such modeling, online instructors may step back and get into an active observer role rather than act as an active participant in student conversations. We understood that although the instructor's presence or involvement in online student discourse was commonly perceived to be important and necessary by the course instructors, their actual practices or experiences still varied. Some instructors might wish to respond to each and every student posting in online discussions, whereas others might prefer to adopt a less active profile to allow students to take ownership of their own discourse. This result also points to contextual and pedagogical variations in instructors' actual experiences of a particular dimension of teaching presence. Given that heavy instructor presence in student conversations may discourage student participation (Dennen et al., 2007), online course instructors may consider adopting a more facilitating and guiding role rather than an active or dominant role in the online student discourse.

The results of our multiple case study also provide supporting evidence that online faculty perceive students' sense of community to be important in online learning environments (Bolliger et al., 2019). Our findings indicate that sense of community is considered valuable by course instructors not only for its affective outcomes but also for its learning outcomes, such as students learning to provide better feedback to their peers. This perception of the positive impact of sense of community on learning outcomes should call for a stronger emphasis within the CoI framework on online course instructors' fostering and supporting students' sense of community through their teaching presence behaviors, including but not limited to facilitating student discourse. We also understood that some instructors might feel more confident or happier about their ability to foster a sense of community among their online learners, while others might still need support and/or professional training. This finding similarly points to potential variations in actual experiences of teaching presence across online contexts and course instructors. Given that fostering and maintaining a strong sense of community can contribute to successful online learning experiences (Berry, 2019; Rovai, 2002), such professional training may be considered seriously by both course instructors and online education leaders including institutions offering online programs and degrees.

The results of this study also highlight that a wide range of assessments and grading approaches were used by the instructors. Assessment is a significant component of online instructional practices, and it can be subsumed by the direct instruction component of CoI's teaching presence because online instructors can provide direct instruction in the form of assessment and feedback statements as well (Anderson et al., 2001). The most significant variation in actual experiences of this teaching presence dimension of direct instruction including assessment in this study was a self-regulated un-grading approach. This approach, unlike 
traditional approaches to assessment and grading, was used by two instructors. The most fundamental component of this un-grading approach is the iterative feedback loops that continually inform the students how to improve their work rather than grading their work as a final product. Such an un-grading approach could be used especially in courses in which gradual progress of student work needs to be encouraged and maintained without the worry or concern over getting a poor grade along the way. This approach may especially work well for assignments that students can declare as "complete" using a checklist, as opposed to rating/ranking with a rubric. Instead of grading every assignment in an online course based on a rubric, instructors may use freeform feedback without any rubrics. We understand that such an un-grading approach might sound too flexible or lenient to some online educators. Considering the student ownership of the learning process, however, such an approach to assessment and grading could be considered as a promising alternative in online learning assessment. This significant deviation from traditional approaches to online assessment and grading also points to the importance of considering contextual characteristics and pedagogical orientations while interpreting teaching presence and its manifestations in online learning environments.

Overall, the results of this case study indicated that teaching presence with all its components might be uniformly perceived to be important and essential by online course instructors, but their actual experiences might significantly vary depending on specific contextual factors and pedagogical orientations. We consider this to be an important conclusion because it indicates that there might not be a single one-size-fits-all teaching presence construct as it is very likely to change while manifesting itself in diverse ways across online teaching contexts and instructors.

\section{Limitations and Future Research}

As in any research studies, this study also had some limitations. First, the study findings should be interpreted with caution when transferring this new knowledge into different settings given that the findings are context-dependent. Second, the qualitative research literature suggests that there are multiple ways of triangulating data such as using multiple theories, data sources, or researchers (e.g., Creswell \& Poth, 2018; Maxwell, 2013). In this study, we only used interviews as data collection tools and triangulated our findings through the lenses of multiple researchers. For future research, we suggest using different data sources or theories that might provide various insights into the study phenomenon and address the validity of the data. Third, given the limited time we had for the data collection and availability of the participants, we could not do member checking for confirmation of our interpretations of the findings.

Based on the findings of this study, we offer further lines of inquiry for future research. First, future research should include further explorations of individual and contextual variations in instructors' perceptions and experiences of teaching presence across online courses and programs in the context of higher education. Second, the online education literature has strong emphasis on quantitative research by addressing a priori assumptions. As reflected in the findings of this study, qualitative research offers rich descriptions of the study phenomenon, which indicates the high demand to build a bridge between quantitative and qualitative approaches to gain a more complete understanding. Accordingly, we recommend that future researchers consider using mixed methods approaches to study such significant online learning variables as CoI presences, including teaching presence, and intentionally integrate the quantitative results with qualitative findings. 


\section{Conclusion}

This multiple case study explained how different instructors teaching different courses online might perceive and experience teaching presence and its dimensions in online learning environments. The instructors perceived teaching presence and its different dimensions to be important, and yet the ways they experienced teaching presence and its components varied across instructors and their specific online teaching contexts. The results of this case study indicate that there might be no one-size-fits-all teaching presence because pedagogical beliefs, instructor preferences, and instructional orientations, as well as specific course contexts and contextual factors, would very likely lead to variations in course instructors' perceptions and experiences of teaching presence and its dimensions. If we aim to achieve a thorough understanding and draw a complete picture of teaching presence in online learning environments, such individual and contextual variations need to be incorporated into this picture. It is our hope that this study adds to the still growing knowledge base about perceptions and experiences of teaching presence and its manifestations explored from instructors' perspectives.

\section{Acknowledgements}

The detailed and insightful feedback of the editors and two anonymous reviewers of the special issue are gratefully acknowledged.

\section{Declarations}

The authors declared no potential conflicts of interest with respect to the research, authorship, and/or publication of this article.

The authors received approval from the ethics review board of the University of Oklahoma, USA for this study.

The authors received no financial support for the research, authorship, and/or publication of this article. 


\section{References}

Anderson, T., Rourke, L., Garrison, D. R., \& Archer, W. (2001). Assessing teaching presence in a computer conferencing context. Journal of Asynchronous Learning Networks, 5(2), 1-17. https://auspace.athabascau.ca/handle/2149/725

Arbaugh, J. B. (2008). Does the Community of Inquiry framework predict outcomes in online MBA courses? International Review of Research in Open and Distance Learning, 9(2), 1-21. eric. https://doi.org/10.19173/irrodl.v9i2.490

Arbaugh, J. B. (2014). System, scholar or students? Which most influences online MBA course effectiveness? Journal of Computer Assisted Learning, 30(4), 349-362. https://doi.org/10.1111/jcal.12048

Berry, S. (2019). Faculty perspectives on online learning: The instructor's role in creating community. Online Learning, 23(4), 181-191. https://doi.org/10.24059/olj.v23i4.2038

Bolliger, D. U., Shepherd, C. E., \& Bryant, H. V. (2019). Faculty members' perceptions of online program community and their efforts to sustain it. British Journal of Educational Technology, 50(6), 3283-3299. https://doi.org/10.1111/bjet.12734

Caskurlu, S., Maeda, Y., Richardson, J. C., \& Lv, J. (2020). A meta-analysis addressing the relationship between teaching presence and students' satisfaction and learning. Computers \& Education, 157, 1-16. https://doi.org/10.1016/j.compedu.2020.103966

Creswell, J. W., \& Poth, C. N. (2018). Qualitative inquiry \& research design: Choosing among five approaches (4th ed.). Sage.

Ezzy, D. (2002). Qualitative analysis: Practice and innovation. Routledge.

Garrison, D. R. (2011). E-learning in the 21st century (2nd ed.). Routledge.

Garrison, D. R., \& Akyol, Z. (2013). The community of inquiry theoretical framework. In M. G. Moore (Ed.), Handbook of distance education (pp. 104-119). Routledge.

Garrison, D. R., Anderson, T., \& Archer, W. (2000). Critical inquiry in a text-based environment: Computer conferencing in higher education. The Internet and Higher Education, 2(2), 87-105. https://doi.org/10.1016/S1096-7516(00)00016-6

Garrison, D. R., \& Arbaugh, J. B. (2007). Researching the community of inquiry framework: Review, issues, and future directions. The Internet and Higher Education, 10(3), 157-172. https://doi.org/10.1016/j.iheduc.2007.04.001 
Garrison, D. R., Cleveland-Innes, M., \& Fung, T. S. (2010). Exploring causal relationships among teaching, cognitive and social presence: Student perceptions of the community of inquiry framework. The Internet and Higher Education, 13(1-2), 31-36.

https://doi.org/10.1016/j.iheduc.2009.10.002

Gurley, L. E. (2018). Educators' preparation to teach, perceived teaching presence, and perceived teaching presence behaviors in blended and online learning environments. Online Learning, 22(2), 197-220. http://dx.doi.org/10.24059/olj.v22i2.1255

Harding, S. (1992). Rethinking standpoint epistemology: What is "strong objectivity"? The Centennial Review, 36, 437-470. http://www.jstor.org/stable/23739232

Ke, F. (2010). Examining online teaching, cognitive, and social presence for adult students. Computers \& Education, 55(2), 808-820. https://doi.org/10.1016/j.compedu.2010.03.013

Kozan, K., \& Richardson, J. C. (2014). Interrelationships between and among social, teaching, and cognitive presence. The Internet and Higher Education, 21, 68-73. https://doi.org/10.1016/j.iheduc.2013.10.007

Kupczynski, L., Ice, P., Wiesenmayer, R., \& McCluskey, F. (2010). Student perceptions of the relationship between indicators of teaching presence and success in online courses. Journal of Interactive Online Learning, 9(1), 23-43. http://www.ncolr.org/jiol/issues/pdf/9.1.2.pdf

Li, J., Wong, S. C., Yang, X., \& Bell, A. (2020). Using feedback to promote student participation in online learning programs: Evidence from a quasi-experimental study. Educational Technology Research and Development, 68(1), 485-510. https://doi.org/10.1007/s11423-019-09709-9

Martin, F., Budhrani, K., Kumar, S., \& Ritzhaupt, A. (2019). Award-winning faculty online teaching practices: Roles and competencies. Online Learning, 23(1), 184-205. https://doi.org/10.24059/olj.v23i1.1329

Maxwell, J. A. (2013). Qualitative research design: An interactive approach (3rd ed.). Sage. Orcutt, J. M., \& Dringus, L. P. (2017). Beyond being there: Practices that establish presence, engage students and influence intellectual curiosity in a structured online learning environment. Online Learning, 21(3), 15-35. https://doi.org/10.24059/olj.v\%vi\%i.1231

Ponterotto, J. G. (2005). Qualitative research in counseling psychology: A primer on research paradigms and philosophy of science. Journal of Counseling Psychology, 52(2), 126-136. https://doi.org/10.1037/0022-0167.52.2.126

Richardson, J. C., Besser, E., Koehler, A., Lim, J., \& Strait, M. (2016). Instructors' perceptions of instructor presence in online learning environments. International Review of Research in Open and Distributed Learning, 17(4), 82-104. https://doi.org/10.19173/irrodl.v17i4.2330 
Richardson, J. C., Koehler, A. A., Besser, E. D., Caskurlu, S., Lim, J., \& Mueller, C. M. (2015). Conceptualizing and investigating instructor presence in online learning environments. International Review of Research in Open and Distributed Learning, 16(3), 256-297. https://doi.org/10.19173/irrodl.v16i3.2123

Richardson, J. C., Maeda, Y., Lv, J., \& Caskurlu, S. (2017). Social presence in relation to students' satisfaction and learning in the online environment: A meta-analysis. Computers in Human Behavior, 71, 402-417. https://doi.org/10.1016/j.chb.2017.02.001

Rovai, A. P. (2001). Building classroom community at a distance: A case study. Educational Technology Research and Development, 49(4), 33-48. https://doi.org/10.1007/BF02504946

Rovai, A. P. (2002). Sense of community, perceived cognitive learning, and persistence in asynchronous learning networks. The Internet and Higher Education, 5(4), 319-332. https://doi.org/10.1016/S1096-7516(02)00130-6

Ryan, R. M., \& Deci, E. L. (2000). Intrinsic and extrinsic motivations: Classic definitions. and new directions. Contemporary Educational Psychology, 25(1), 54-67. https://doi.org/10.1006/ceps.1999.1020

Ryan, R. M., \& Deci, E. L. (2017). Self-determination theory: Basic psychological needs in motivation, development, and wellness. The Guilford Press.

Shea, P. (2006). A study of students' sense of learning community in online environments. Online Learning Journal, 10(1), 35-44. https://doi.org/10.24059/olj.v10i1.1774.

Shea, P., \& Bidjerano, T. (2009). Community of inquiry as a theoretical framework to foster "epistemic engagement" and "cognitive presence" in online education. Computers \& Education, 52(3), 543-553. https://doi.org/10.1016/j.compedu.2008.10.007

Shea, P., Li, C. S., Swan, K., \& Pickett, A. (2005). Developing learning community in online asynchronous college courses: The role of teaching presence. Journal of Asynchronous Learning Networks, 9(4), 59-82. https://doi.org/10.24059/olj.v9i4.1779

Shea, P., Li, C.S., \& Pickett, A. (2006). A study of teaching presence and student sense of learning community in fully online and web-enhanced college courses. The Internet and Higher Education, 9(3), 175-190. https://doi.org/10.1016/j.iheduc.2006.06.005

Sherblom, J. C. (2010). The computer-mediated communication (CMC) classroom: A challenge of medium, presence, interaction, identity, and relationship. Communication Education, 59(4), 497-523. https://doi.org/10.1080/03634523.2010.486440

Watson, S. L., Watson, W. R., Janakiraman, S., \& Richardson, J. (2017). A team of instructors' use of social presence, teaching presence, and attitudinal dissonance strategies: An animal behaviour and welfare MOOC. International Review of Research in Open and Distributed Learning, 18(2), 68-91. https://doi.org/10.19173/irrodl.v18i2.2663 
Yin, R. K. (2018). Case study research and applications: Design and methods (6th ed.). Sage.

Zhang, H., Lin, L., Zhan, Y., \& Ren, Y. (2016). The impact of teaching presence on online engagement behaviors. Journal of Educational Computing Research, 54(7), 887-900. https://doi.org/10.1177/0735633116648171 